\title{
Легирование углеродных нанослоев, выращенных импульсным лазерным методом
}

\author{
(C) Ю.А. Данилов ${ }^{1}$, А.В. Алафрердов ${ }^{1,2}$, О.В. Вихрова ${ }^{1}$, Д.А. Здоровейщев ${ }^{1}$, В.А. Ковальский ${ }^{3}$, \\ Р.Н. Крюков ${ }^{1}$, Ю.М. Кузнецов ${ }^{1}$, В.П. Лесников ${ }^{1}$, А.В. Нежданов ${ }^{1}$, М.Н. Дроздов ${ }^{4}$ \\ ${ }^{1}$ Нижегородский государственный университет им. Н.И. Лобачевского, \\ 603022 Нижний Новгород, Россия \\ ${ }^{2}$ Center for Semiconductor Components and Nanotechnologies, University of Campinas, \\ 13083-870 Campinas, SP, Brazil \\ ${ }^{3}$ Институт проблем технологии микроэлектроники и особочистых материалов Российской академии наук, \\ 142432 Черноголовка, Московская область, Россия \\ ${ }^{4}$ Институт фризики микроструктур Российской академии наук, \\ 607680 Нижний Новгород, Россия \\ E-mail: danilov@nifti.unn.ru
}

Поступила в Редакцию 9 апреля 2021 г.

В окончательной редакции 19 апреля 2021 г.

Принята к публикации 19 апреля 2021 г.

Исследованы возможности легирования углеродных слоев, выращиваемых методом импульсного лазерного нанесения, примесями переходных металлов. Изучены состав, оптические и электрические параметры структур на подложках $\mathrm{GaAs}$ и $\mathrm{Si} / \mathrm{SiO}_{2}$. Показано, что введение таких атомов, как $\mathrm{Fe}$, модифицирует магнитные свойства слоев, вызывая нелинейные магнитополевые зависимости эффекта Холла при температурах вплоть до $300 \mathrm{~K}$.

Ключевые слова: импульсное лазерное нанесение, углеродные слои, легирование, примеси переходных металлов.

DOI: $10.21883 /$ FTP.2021.08.51128.04

\section{1. Введение}

Интерес к углеродной наноэлектронике связан с уникальными электрофизическими свойствами таких материалов, как графен и углеродные нанотрубки. В связи с перспективами развития устройств на их основе актуальными становятся вопросы получения углеродных слоев на достаточно большой площади и легирования необходимыми примесями до заданной концентрации. Наиболее приборно-ориентированным методом получения углеродных наноструктур является химическое осаждение из газовой фазы (CVD); в его основе лежит термокаталитическое разложение газообразных углеводородов на поверхности некоторых металлов-катализаторов $(\mathrm{Cu}, \mathrm{Rh}, \mathrm{Ni}, \mathrm{Co})$. Однако непосредственное нанесение углеродных слоев этим способом на приборные структуры невозможно из-за высоких температур процесса, поэтому образованные наноструктуры необходимо для последующего использования перенести с помощью специальных химических приемов на полупроводниковую подложку. Метод импульсного лазерного нанесения (ИЛН $)$ [1] свободен от этого недостатка; кроме того, он обеспечивает достаточно гибкое управление параметрами нанесения (температура подложки и время процесса), обеспечивает высокую чистоту углеродных пленок при вакуумном проведении процесса и позволяет контролируемо легировать их различными примесями путем лазерного распыления подходящих твердотельных источников.
Метод ИЛН используется для получения углеродных слоев в основном двух типов: алмазоподобных пленок (в которых преобладают $s p^{3}$-связи между атомами углерода) [2] и графеновых слоев (с преобладанием $s p^{2}$-гибридизации) [3]. Для нанесения алмазоподобных пленок обычно используются невысокие температуры подложки (типично от +20 до $+75^{\circ} \mathrm{C}$ ), в то время как для формирования графена - высокие температуры процесса (обычно $>700^{\circ} \mathrm{C}$ ) [4] и (или) использование предварительно нанесенных подслоев металлов-катализаторов (Ni, Co и др.) [5]. Для применения слоев графена в приборных структурах на основе GaAs вариант высоких температур не является подходящим, поскольку при $T>500^{\circ} \mathrm{C}$ с поверхности начинает активно испаряться As, что приводит к нарушению стехиометрии в приповерхностных слоях. Вариант использования пленок металлов-катализаторов сильно усложняет технологию, поскольку требуется отделение графена от металла и перенесение его через химическую среду на поверхность полупроводника. Поэтому при использовании ИЛН для непосредственного осаждения на GaAs требуется: вопервых, оптимизировать методику формирования слоев графена; во-вторых, желательно, чтобы методика позволяла легировать углеродные слои в процессе их выращивания. Известны подходы к легированию выращиваемых методом ИЛН слоев графена с помощью напуска в ростовую камеру газообразного азота [6] (получение $n$-типа проводимости) или легирование углеродных слоев бором (получение $p$-типа проводимости) 
при лазерном распылении композитных спрессованных В-C мишеней [7].

В настоящей работе для формирования углеродных слоев использовано импульсное лазерное нанесение в вакууме. Для легирования атомами переходных элементов группы железа в процессе роста использовались мишени, составленные из пластины пирографита и соответствующей металлической пластины.

\section{2. Методика эксперимента}

Основными элементами установки ИЛН являются импульсный лазер, вакуумная камера и система откачки. Излучение лазера АИГ: $\mathrm{Nd}$ (длина волны 532 нм, длительность импульса $10-12 \mathrm{Hc}$, частота повторения 10 Гц, энергия в импульсе 250 мДж) фокусировалось на распыляемой вращающейся мишени, находящейся в вакуумной камере (давление ниже $10^{-6}$ Торр). Температура подложки $\mathrm{GaAs}$ или $\mathrm{Si} / \mathrm{SiO}_{2}$ (пленка $\mathrm{SiO}_{2}$ выращена на $\mathrm{Si}$ термическим окислением), как правило, составляла $500^{\circ} \mathrm{C}$. Толщина нанесенных слоев была в диапазоне 7-20 нм. Источником атомов углерода служил пирографит. Для легирования С-пленок обычно мы использовали распыление мишени, составленной из пирографита с сектором из другого материала (металлических $\mathrm{Fe}$, $\mathrm{Mn}, \mathrm{Co}, \mathrm{Ni}$ или др.). Мишень вращается в вакуумной камере, и след луча распыляющего лазера имеет вид кольца. При этом угол сектора легирующего металла определяет концентрацию вводимой примеси.

Свойства полученных углеродных пленок были исследованы при помощи методов комбинационного рассеяния света (КРС) и рентгеновской фотоэлектронной спектроскопии (РФЭС). Транспортные характеристики были получены из измерений эффекта Холла (в геометрии Ван дер Пау) при комнатной температуре и при $77 \mathrm{~K}$.

Спектры КРС были получены на установке SENTERRA, которая включает в себя модуль рамановского спектрометра с тройным лазером и модуль конфокального микроскопа, при комнатной температуре в геометрии обратного рассеяния. Использовался лазер с длиной волны 532 нм и мощностью 2 мВт; излучение фокусировалось $50 \times$ объективом в пятно диаметром $\sim 2$ мкм. Время экспозиции составляло $400 \mathrm{c}$.

Профили распределений элементов в структурах изучены методом времяпролетной вторичной ионной массспектрометрии (ВИМС) на установке TOF.SIMS-5, имеющей возможность регистрировать широкий диапазон масс. Установка снабжена двумя ионными пушками для зондирования и распыления, работающими в импульсном режиме. Зондирование проводилось кластерными ионами $\mathrm{Bi}^{3+}$ с энергией 25 кэВ и током пучка 0.5 пА. Для распыления использован пучок ионов $\mathrm{Cs}^{+} \mathrm{c}$ энергией 1 кэВ и током пучка 80 нА. В этом случае регистрировались отрицательные вторичные ионы. Калибровка по глубине проводилась при измерении глубины
Таблица 1. Признаки различных фаз в углеродных материалах, установленные экспериментально в [8] по результатам времяпролетной ВИМС (распыление пучком ионов цезия)

\begin{tabular}{l|c|c}
\hline \multicolumn{1}{c|}{ Отношение интенсивностей } & $\mathrm{C}_{8} / \mathrm{C}_{5}$ & $\mathrm{CsC}_{8} / \mathrm{CsC}_{4}$ \\
\hline Алмаз $\left(s p^{3}\right.$-связи) & $>1$ & $>1$ \\
Алмазоподобные пленки & $<1$ & $>1$ \\
(смешанное состояние $s p^{3}$ - и $s p^{2}$-связей $)$ & $<1$ \\
Графит $\left(s p^{2}\right.$-связи $)$ & $<1$ & $<1$
\end{tabular}

вытравленного кратера. Кроме построения распределений элементов по глубине структур, для определения характеристик углеродных слоев использован подход, разработанный в [8]. Подход основан на том, что при регистрации отрицательных ионов отношение интенсивностей определенных кластерных ионов изменяется в зависимости от преобладания $s p^{3}-$ или $s p^{2}$-связей в углеродном материале. Выведенные в [8] соотношения приведены в табл. 1. В настоящей работе они использованы для качественного подтверждения фазового состава углеродных слоев, полученных методом ИЛН.

Метод РФЭС реализован на базе сверхвысоковакуумного комплекса Omicron Multiprobe RM. Для получения спектров использовалось $\mathrm{Al} K_{\alpha}$-излучение. Для определения соотношения концентраций углерода с $s p^{2}$ и $s p^{3}$-гибридизацией производилась запись фотоэлектронной линии С $1 s$. Спектральное разрешение определялось на уровне $0.8-1$ эВ; исходя из этого был выбран шаг 0.2 эВ по оси энергий. Детали этой методики описаны в [9].

\section{3. Результаты экспериментов и их обсуждение}

Исходные нелегированные углеродные слои представляют собой, по данным КРС, совокупность зерен многослойного графена. Слои имеют $p$-тип проводимости (удельное сопротивление $\sim 10^{-2}$ Ом · см). Отметим, что материал подложки оказывает влияние на электрические свойства: систематически поверхностное сопротивление C-слоев на $\mathrm{SiO}_{2}$ ниже, чем на GaAs. Анализ нелегированных углеродных слоев методом РФЭС показал (подробные данные приведены нами в [9]), что С-покрытие на GaAs являлось сплошным. Концентрация углерода в слое составляла $94 \pm 1$ ат\% с небольшим $(6 \pm 1$ ат\%) содержанием кислорода. Соотношение концентраций $s p^{2}$ и $s p^{3}$-гибридизированного углерода зависело от материала подложки и достигало $\sim 5$ для нанесения на $\mathrm{Si} / \mathrm{SiO}_{2}$.

Образцы углеродных слоев, легированных примесями переходных элементов группы железа в процессе ИЛН и исследованных в настоящей работе, можно разделить на две группы: (1) слои с относительно низкой концентрацией (НК-легирование), которые получены при времени процесса 90 с и использовании мишени, составленной 
Таблица 2. Определение концентраций элементов в НК-легированных углеродных слоях методом РФЭС

\begin{tabular}{|c|c|c|c|c|c|c|}
\hline Примесь & $Y_{\mathrm{Me}}$ & Подложка & $\mathrm{C}, \mathrm{aT} \%$ & O, ат\% & Металл, ат\% & $\mathrm{C}\left(s p^{2}\right) / \mathrm{C}\left(s p^{3}\right)$ \\
\hline $\mathrm{Cr}$ & 0.08 & $\begin{array}{l}\mathrm{GaAs} \\
\mathrm{SiO}_{2}\end{array}$ & $\begin{array}{l}89.3 \\
87.6\end{array}$ & $\begin{array}{l}7.8 \\
9.3\end{array}$ & $\begin{array}{c}0.1-0.5 \\
0.5\end{array}$ & $\begin{array}{r}14.6 \\
9.6\end{array}$ \\
\hline $\mathrm{Mn}$ & 0.12 & $\begin{array}{l}\text { GaAs } \\
\mathrm{SiO}_{2} \\
\end{array}$ & $\begin{array}{l}91.4 \\
89.8 \\
\end{array}$ & $\begin{array}{l}6.2 \\
8.4 \\
\end{array}$ & $\begin{array}{c}0.1-0.5 \\
0.8 \\
\end{array}$ & $\begin{array}{l}9.7 \\
4.4 \\
\end{array}$ \\
\hline $\mathrm{Fe}$ & 0.17 & $\begin{array}{l}\mathrm{GaAs} \\
\mathrm{SiO}_{2}\end{array}$ & $\begin{array}{l}91.8 \\
86.5\end{array}$ & $\begin{array}{r}6.0 \\
12.8\end{array}$ & $\begin{array}{l}0.1-0.5 \\
0.1-0.5\end{array}$ & $\begin{array}{l}8.5 \\
4.1\end{array}$ \\
\hline Co & 0.12 & $\begin{array}{l}\mathrm{GaAs} \\
\mathrm{SiO}_{2}\end{array}$ & $\begin{array}{l}88.8 \\
89.9\end{array}$ & $\begin{array}{l}8.0 \\
8.4\end{array}$ & $\begin{array}{l}0.1-0.5 \\
0.1-0.5\end{array}$ & $\begin{array}{r}15.7 \\
4.8\end{array}$ \\
\hline
\end{tabular}

из пластины пирографита и сектора металла с углом $\varphi=30-90^{\circ} ;(2)$ слои со средней концентрацией (СКлегирование), которые сформированы при времени процесса 180 с и мишени, составленной из двух половинок - пирографита и пластины металла. Поскольку угол металлического сектора отличался от образца к образцу, то условно можно характеризовать содержание металла величиной $Y_{\mathrm{Me}}=\varphi / 360$. Эта величина, по существу, имеет смысл обозначения, но не оценки концентрации, поскольку скорость лазерного распыления пирографита значительно выше, чем скорость распыления металлов. По оценкам, для $\mathrm{Ni}$ и наших режимов лазерного распыления эта разница превышает 20 раз. Поэтому при использовании сектора 30-90 (НК-легирование) содержание металлов ожидается на уровне $<1$ ат\%.

\section{1. Низкоконцентрационное легирование углеродных слоев}

Действительно, при исследовании методом ВИМС образца, легированного железом $\left(Y_{\mathrm{Fe}}=0.17\right)$, атомы $\mathrm{Fe}$ не обнаруживаются на всем протяжении углеродного слоя. Профиль углерода подобен приведенному в [9] профилю для нелегированного слоя на подложке GaAs; практически совпадает и толщина слоя $(\sim 11 \mathrm{нм})$, хотя в случае С-слоя [9] время нанесения составляло 60 с. Это объяснимо, принимая во внимание уменьшение суммарного времени распыления пирографита из-за введения сектора металлического $\mathrm{Fe}$ (полное время процесса распыления составной мишени равно $90 \mathrm{c}$ ). Присутствие мышьяка такое же, как и для нелегированного образца, наблюдается в углеродном слое (концентрация As падает в 100 раз на расстоянии $\sim 1.5$ нм от номинальной границы раздела $\mathrm{C} / \mathrm{GaAs})$.

В табл. 2 приведены данные о составе, полученные при исследовании НК-легированных углеродных слоев методом РФЭС. Сумма концентраций углерода, кислорода и металла составляет $<100$ ат\%, поскольку в таблице не приведены значения содержания элементов, входящих в слой из подложек. Так, для углеродных слоев на подложке GaAs отмечается содержание атомов $\mathrm{Ga}$ и As от 1.1 до $1.6 \mathrm{aT} \%$; для слоев на $\mathrm{Si} / \mathrm{SiO}_{2}$-подложке содержание кремния составляет 0.7-2.6 ат\%. Отметим, что регистрация сигнала от подложки в исследуемых системах может объясняться конечной глубиной анализа в методе РФЭС [10], которая может достигать $>10$ нм. Кислород на поверхности углеродных слоев появляется преимущественно из-за хранения образцов на воздухе, хотя небольшое увеличение (максимум до 6.8 ат\%) его концентрации можно наблюдать для подложек $\mathrm{Si} / \mathrm{SiO}_{2}$ по сравнению с подложками GaAs.

Необходимо отметить, что как для легированных, так и для нелегированных образцов на подложках $\mathrm{GaAs}$ систематически наблюдалось повышенное по сравнению с пленками на $\mathrm{Si} / \mathrm{SiO}_{2}$ значение отношения $\mathrm{C}\left(s p^{2}\right) / \mathrm{C}\left(s p^{3}\right)$. Природа этого экспериментального факта на сегодняшний день не имеет объяснения.

В литературе результатов исследований ИЛН углеродных слоев, нанесенных при высоких температурах на подложки GaAs, не обнаружено.

\section{2. Среднеконцентрационное легирование}

При увеличении металлического сектора на распыляемой лазером мишени до $180^{\circ}$ (СК-легирование) примеси в углеродном слое обнаруживаются легко как методом ВИМС, так и РФЭС. На рис. 1, $a$ показаны ВИМС-профили атомов углерода (регистрировался ряд отрицательных ионов, приведено распределение кластерного $\mathrm{C}_{8}$ ), мышьяка (регистрировались кластеры $\mathrm{GaAs}$ ) и железа (регистрировались кластеры $\mathrm{C}_{2} \mathrm{Fe}$ c массой 80 о.а.е.м.) в углеродных слоях, выращенных в течение 180 с при $Y_{\mathrm{Fe}}=0.5$ на подложке GaAs. Исходя из рис. $1, a$ толщину углеродной СК-легированной пленки можно оценить значением 15 нм. Распределение мышьяка более пологое к поверхности по сравнению с нелегированным образцом (спад сигнала кластера GaAs на 2 порядка величины на расстоянии 2.5 нм от границы раздела $\mathrm{C} / \mathrm{GaAs}$ против 1.5 нм для нелегированного и НК-легированного слоев).

Профиль атомов $\mathrm{Fe}$ имеет следующие особенности: падение концентрации в приповерхностном слое толщиной 1-2 нм (очевидно, из-за присутствия поверхностных загрязнений), накопление на границе раздела $\mathrm{C} / \mathrm{GaAs}$ и 
Таблица 3. Определение концентраций элементов в СК-легированных $\left(Y_{\mathrm{Me}}=0.5\right)$ углеродных слоях методом РФЭС

\begin{tabular}{c|c|c|c|c|r}
\hline Примесь & Подложка & $\mathrm{C}$, ат\% & О, ат\% & Металл, ат\% & $\mathrm{C}\left(s p^{2}\right) / \mathrm{C}\left(s p^{3}\right)$ \\
\hline \multirow{2}{*}{$\mathrm{Mn}$} & $\mathrm{GaAs}$ & 90.29 & 7.59 & 0.57 & 11.3 \\
& $\mathrm{SiO}_{2}$ & 88.01 & 9.30 & 1.39 & 6.9 \\
\hline \multirow{2}{*}{$\mathrm{Fe}$} & $\mathrm{GaAs}^{*}$ & 88.74 & 8.29 & 0.66 & 14.6 \\
& $\mathrm{SiO}_{2}$ & 89.55 & 9.06 & 0.71 & 17.9 \\
\hline \multirow{2}{*}{$\mathrm{Co}$} & $\mathrm{GaAs}^{*} \mathrm{Ni}$ & 90.81 & 7.56 & 0.52 & 8.3 \\
\hline \multirow{2}{*}{$\mathrm{SiO}$} & & & & 10.8 \\
& $\mathrm{GaAs}^{2}$ & 90.98 & 6.61 & 0.17 & 7.6
\end{tabular}

диффузионное расплывание Fе от этой границы в глубь полупроводника на $\sim 9$ нм (уменьшение интенсивности сигнала на 2 порядка величины). Профиль углерода гораздо более резкий: сигнал спадает от границы раздела
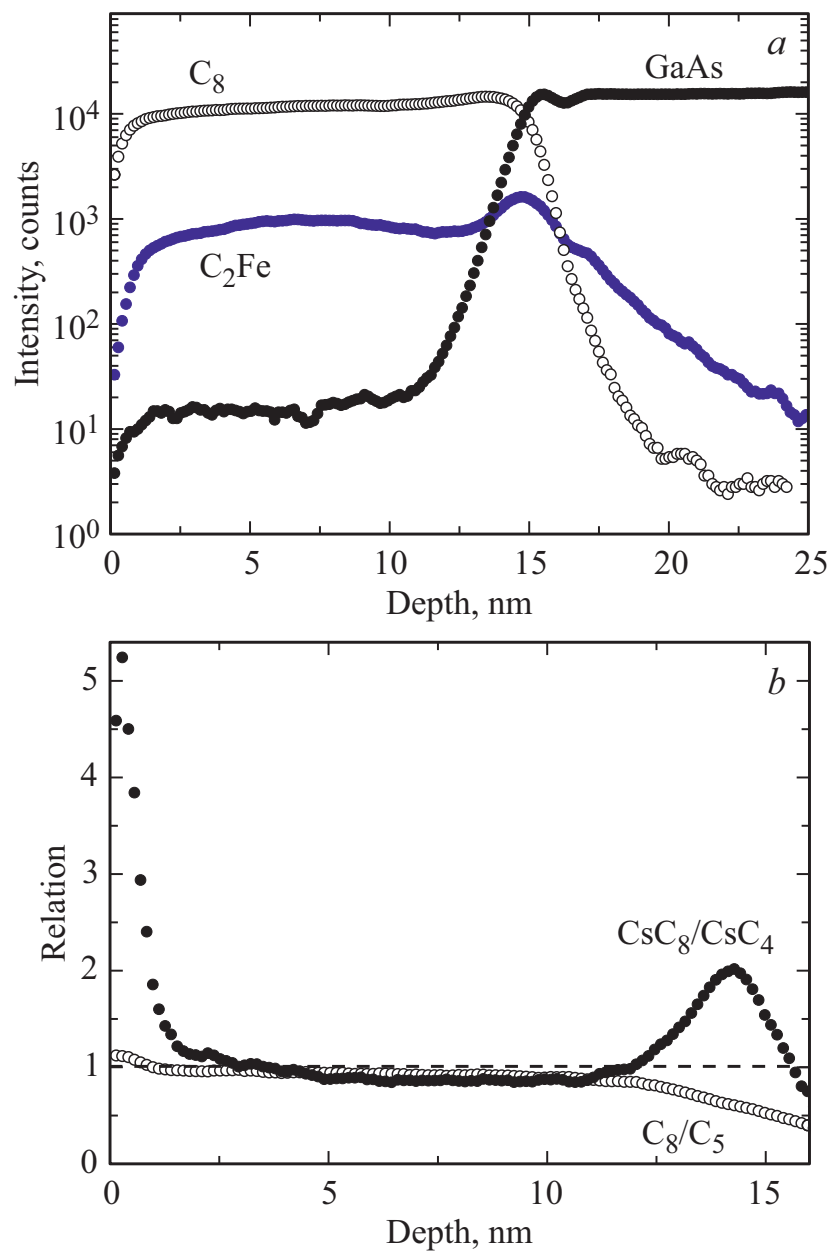

Рис. 1. (а) ВИМС-профили распределения атомов углерода $\left(\mathrm{C}_{8}\right)$, железа $\left(\mathrm{C}_{2} \mathrm{Fe}\right)$ и мышьяка $(\mathrm{GaAs})$ в структуpe $\mathrm{C}: \mathrm{Fe} / i-\mathrm{GaAs}(001)$, полученной в течение 180 с при СКлегировании; $(b)$ Профили отношений $\mathrm{C}_{8} / \mathrm{C}_{5}$ и $\mathrm{CsC}_{8} / \mathrm{CsC}_{4}$ по глубине того же углеродного слоя. Распыление ионами Cs c энергией 1 кэВ. в GaAs на 2 порядка величины на расстоянии 2 нм. Ввиду отсутствия эталонов Fе в углеродных слоях определение абсолютной концентрации железа из данных ВИМС не представлялось возможным.

Метод РФЭС позволил сделать оценки концентрации атомов переходных элементов в легированных углеродных слоях (см. табл. 3). Так, содержание Fе оценивается значением $\sim 0.7$ ат\%. Несколько выше концентрация $\mathrm{Mn}$, и ниже - кобальта. Самое низкое значение $(\sim 0.2$ ат\%) получено для Ni. Видимо, скорость лазерного распыления никеля минимальна из числа изученных металлов. Обращает на себя внимание факт значительного различия содержания Мn в углеродных слоях на GaAs и на $\mathrm{Si} / \mathrm{SiO}_{2}$. Известно [11], что Мn может быстро диффундировать в $\mathrm{GaAs}$ даже при $500^{\circ} \mathrm{C}$, а пленка $\mathrm{SiO}_{2}$ является для него диффузионным барьером. Уход атомов Mn в GaAs-подложку может вызвать подобное различие.

Из табл. 3 также можно видеть, что отношение $\mathrm{C}\left(s p^{2}\right) / \mathrm{C}\left(s p^{3}\right)$ выросло для СК-легированных слоев по сравнению с соответствующим отношением в случае низкого легирования, причем это справедливо как для GaAs-подложек, так и для $\mathrm{Si} / \mathrm{SiO}_{2}$. Отметим увеличение относительного содержания $s p^{2}$-связей углерода для СКлегированных железом слоев до 14.6 (GaAs-подложки) и $8.3\left(\mathrm{Si} / \mathrm{SiO}_{2}\right)$. Рис. 2 показывает спектры фотоэлектронной линии С $1 s$ для нелегированного (рис. 2,a) и легированного $\mathrm{Fe}$ (рис. $2, b)$ углеродного слоя. Точками на рис. 2, $a$ и $b$ показаны экспериментальные значения, а линии представляют собой компоненты спектрального разложения линии С $1 s$. Видно, что основная часть углерода находится в элементном состоянии. Суммарная концентрация углерода, химически связанного с кислородом, невелика (до 4 ат\%). В обоих случаях (рис. 2, $a$ и $b)$ при разложении было выявлено наличие пика, ассоциированного с $\pi-\pi^{*}$ плазмонами и характерного для образцов графита с хорошей электрической проводимостью. Видно также, что соотношение концентраций компонент разложения $\mathrm{C}\left(s p^{2}\right)$ и $\mathrm{C}\left(s p^{3}\right)$ увеличивается при легировании в пользу $s p^{2}$-связей. Расчет соотношения $\mathrm{C}\left(s p^{2}\right) / \mathrm{C}\left(s p^{3}\right)$ для приведенных на рис. 2 спектров 
дает значения 5.1 для нелегированного углеродного слоя и 10.5 для $\mathrm{C}: \mathrm{Fe}$ слоя.

С этим результатом качественно согласуется ВИМСпрофилирование кластерных ионов для СК-легированного углеродного слоя. На рис. $1, b$ показаны профили отношений $\mathrm{C}_{8} / \mathrm{C}_{5}$ и $\mathrm{CsC}_{8} / \mathrm{CsC}_{4}$. Видно, что на основной части профиля (на глубинах от 3 до 12 нм) указанные отношения меньше единицы. Это, согласно [8], свидетельствует о преобладании $s p^{2}$-гибридизации атомов углерода (см. табл. 1) в слое. Возрастание отношения $\mathrm{CsC}_{8} / \mathrm{CsC}_{4}$ на приповерхностном участке и вблизи границы раздела $\mathrm{C} / \mathrm{GaAs}$ может быть связано с загрязнениями (например, атомами кислорода) при хранении образца и (или) при загрузке подложки в вакуумную камеру.

На рис. 3 показаны спектры КРС для структур с углеродными слоями на подложке $\mathrm{Si} / \mathrm{SiO}_{2}$, нанесенными при практически идентичных по отношению к углероду условиях процесса ИЛН: температура подложки $T=500^{\circ} \mathrm{C}$, время нанесения $100 \mathrm{c}$ (нелегированный образец) и $180 \mathrm{c}$ (образец, легированный $\mathrm{Fe}$ при $\varphi=180^{\circ}$ ). Анализ полу-
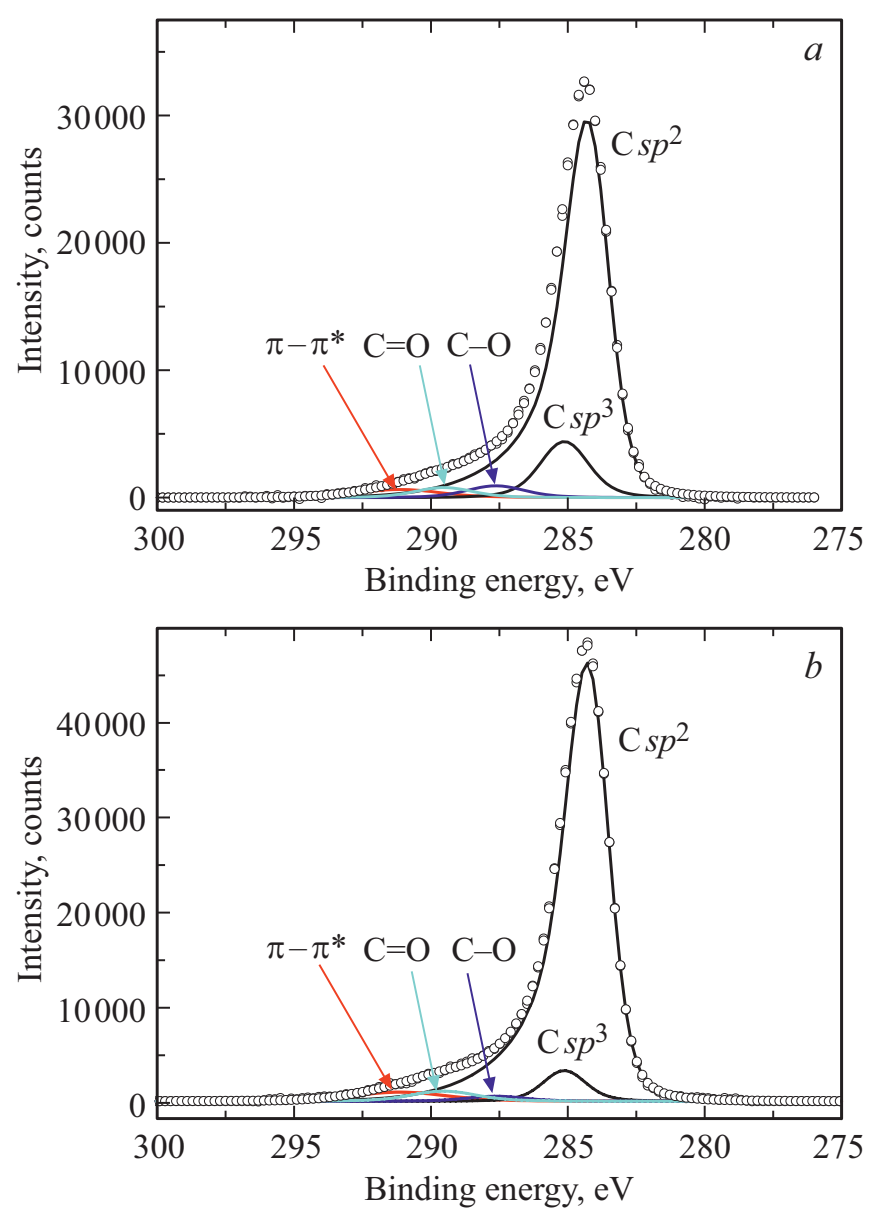

Pис. 2. Спектры фотоэлектронной линии С $1 s$, полученные методом РФЭС для углеродных слоев, нанесенных без легирования $(a)$ и с СК-легированием $\mathrm{Fe}(b)$. Подложка $\mathrm{Si} / \mathrm{SiO}_{2}$. Кружки представляют экспериментальные точки, а линии спектральные разложения.

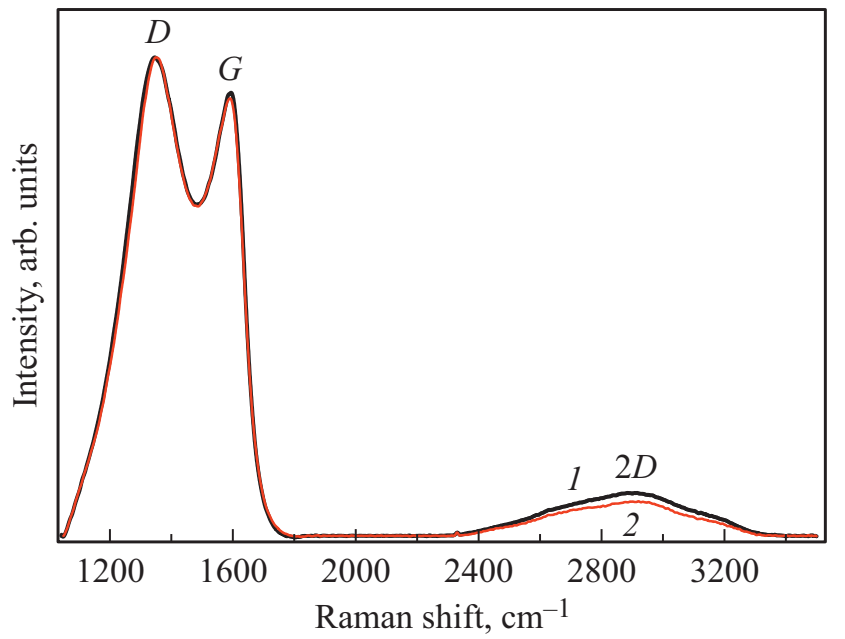

Рис. 3. Спектры комбинационного рассеяния света для углеродных слоев: кривая $1-$ нелегированный образец; кривая 2 - слой, СК-легированный Fе. Спектры представлены после вычета фона и нормированы на интенсивность D линии.

ченных спектров КРС показал наличие трех основных линий: связанная с наличием дефектов в графеновой плоскости D линия, типичная для всех графитоподобных материалов $\mathrm{G}$ линия и 2D линия (обертон D), форма которой также может указывать на количество слоев и степень графитизации $[12,13]$. Структура спектра КРС указывает на довольно высокую степень кристаллографического беспорядка как в нелегированном, так и в легированном образце. Именно на это указывает значительно уширенная $\mathrm{G}$ линия (переходящая в $\mathrm{D}$ ), a также высокое отношение интегральных интенсивностей этих линий $I_{\mathrm{D}} / I_{\mathrm{G}}$, которое принято использовать как меру беспорядка в графеновых слоях [14].

Деконволюция пиков D и $\mathrm{G}$ показала, что каждый из них имеет по две компоненты, интерпретация которых будет задачей наших последующих исследований. Отметим, что положения пиков D (1350 и $\left.1353 \mathrm{~cm}^{-1}\right)$ и $\mathrm{G}\left(1584\right.$ и $1582 \mathrm{~cm}^{-1}$ в нелегированном и Fе-легированном слоях соответственно) практически совпадают, a отношения $I_{\mathrm{D}} / I_{\mathrm{G}}$ близки для нелегированного и $\mathrm{Fe}-$ легированного слоя (1.49 и 1.51 соответственно).

Спектры КРС при легировании углеродных слоев другими переходными металлами $(\mathrm{Cr}, \mathrm{Mn}, \mathrm{Co}, \mathrm{Ni})$ не отличаются от спектров для Fe-легирования. Отсюда можно заключить, что СК-легирование переходными металлами по крайней мере не ухудшало структуру углеродных слоев.

Ранее [9] было указано, что корректное определение по измерениям эффекта Холла типа проводимости, концентрации свободных носителей и их подвижности в углеродных пленках, полученных методом ИЛН, затруднено; есть смысл ограничиться измерением поверхностного сопротивления $\left(R_{s}\right)$. При времени нанесения нелегированного углеродного слоя $t=90$ с значение $R_{s}$ 
составляет $\sim 8900$ Ом/квадрат для подложки $\mathrm{Si} / \mathrm{SiO}_{2}$ и 9500 Ом/квадрат для GaAs.

При НК-легировании атомами переходных элементов поведение $R_{s}$ сильно зависит от типа примеси и от подложки. В частности, при легировании атомами Со углеродный слой становится более низкоомным на подложке $\mathrm{Si} / \mathrm{SiO}_{2} \quad\left(R_{S}\right.$ уменьшается на порядок величины до 780 Ом/квадрат) и более высокоомным на GaAs $\left(R_{s}\right.$ увеличивается до $23700 \mathrm{OM} /$ квадрат). Для легирования никелем на подложке $\mathrm{Si} / \mathrm{SiO}_{2}$ значение $R_{s}$ также уменьшается по сравнению с нелегированным слоем, но не так сильно, как в случае Со: лишь до 6400 Ом/квадрат. Для подложки GaAs углеродный слой, НК-легированный $\mathrm{Ni}$, имеет поверхностное сопротивление 16600 Ом/квадрат (выше, чем для нелегированного образца). Холловская разность потенциалов для исследованных структур небольшая в полях вплоть до 1.5 Тл: холловское сопротивление не выше 1-2Ом и трудно определяется на фоне шумов. Измерения знака термоэдс для $\mathrm{Ni}$ - и Со-легированных слоев в большинстве случаев показывают $p$-тип проводимости. Однако для структуры $\mathrm{C}: \mathrm{Co} / \mathrm{GaAs}$ эффект Зеебека не измеряется; вероятно, потому что концентрации электронов и дырок приблизительно равны, а их подвижности низкие.

Отметим увеличение поверхностного сопротивления при понижении температуры измерений до $77 \mathrm{~K}$ : на подложке $\mathrm{Si} / \mathrm{SiO}_{2}$ для легирования $\mathrm{Co}$ - до 27500 Ом/квадрат и для $\mathrm{Ni}$ - до 21000 Ом/квадрат; на подложке GaAs - до 44500 и 47200 Ом/квадрат при легировании Со и $\mathrm{Ni}$ соответственно. Увеличение $R_{s}$ при снижении температуры измерений коррелирует с полупроводниковым характером температурной зависимости сопротивления нелегированных углеродных слоев подобного типа [9] и соответствует также поведению температурной зависимости сопротивления для образцов графита с высоким содержанием дефектов [15-17].

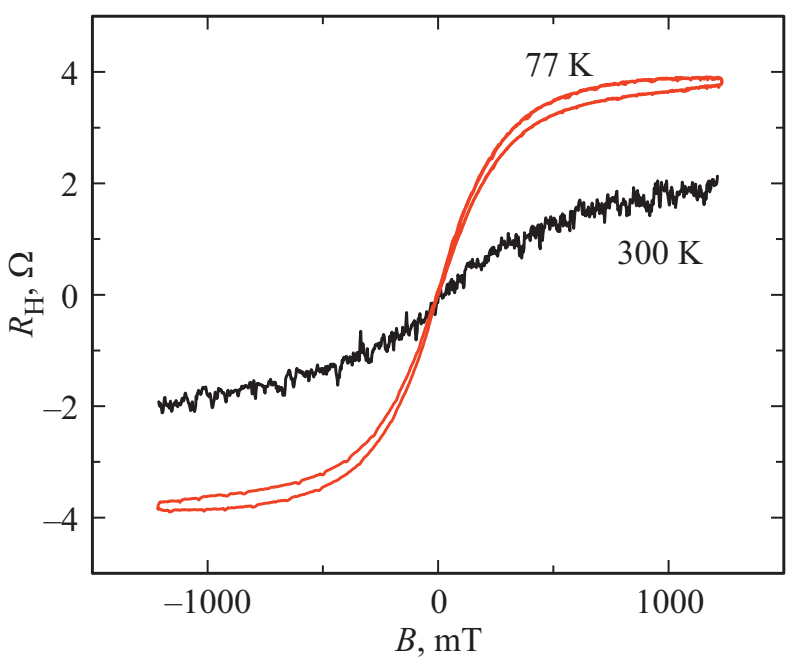

Рис. 4. Магнитополевые зависимости сопротивления Холла для структуры $\mathrm{C}: \mathrm{Fe} / \mathrm{SiO}_{2}$ с концентрацией железа $\sim 0.7$ ат.\%.
В случае СК-легирования для всех углеродных структур, кроме легированной $\mathrm{Ni}$, наблюдалось уменьшение поверхностного сопротивления по сравнению с нелегированным слоем, особенно заметное для подложек $\mathrm{Si} / \mathrm{SiO}_{2}$. Так, для легирования Со значения $R_{s}$ составляли 6030 и 8130 Ом/квадрат, соответственно, для углеродных слоев на $\mathrm{Si} / \mathrm{SiO}_{2}$ и GaAs. Таким образом, из сравнения результатов для НК- и СК-легирования с исходными структурами следует, что зависимость сопротивления слоев от степени легирования металлическими примесями явно немонотонная, на нее влияет тип примеси и материал подложки, и это требует дополнительного изучения. В большинстве легированных структур измерения эффекта Зеебека демонстрировали $p$-тип проводимости.

Для структуры $\mathrm{C}: \mathrm{Fe} / \mathrm{SiO}_{2}$ как при комнатной температуре измерений, так и при $77 \mathrm{~K}$ наблюдался аномальный эффект Холла. На рис. 4 показана магнитополевая зависимость сопротивления Холла. Нелинейная зависимость эффекта Холла позволяет надеяться на появление ферромагнитных свойств углеродных слоев, легированных переходными элементами (в первую очередь Fe) при оптимизации условий их формирования методом ИЛН.

\section{4. Заключение}

Таким образом, показано, что легирование углеродных слоев в процессе их импульсного лазерного нанесения достаточно легко реализуемо и может привести к модифицированию свойств слоев. Углеродные слои, легированные атомами переходных металлов, по измерениям термоэдс обнаруживают преимущественно $p$-тип проводимости так же, как и исходные нелегированные $C$-слои. Исследования эффекта Холла показали, что при легировании $\mathrm{Fe}$ наблюдается нелинейная магнитополевая зависимость для структур на подложках $\mathrm{Si} / \mathrm{SiO}_{2}$, свидетельствующая о появлении специфических (вероятно, ферромагнитных) свойств углеродных слоев. Исследованы профили распределения углерода и легирующего Fe в структурах на подложке GaAs. Рентгеновская фотоэлектронная спектроскопия демонстрирует увеличение отношения концентраций $s p^{2}$ и $s p^{3}$ связанного углерода при легировании переходными металлами. Таким образом, легирование углеродных пленок в процессе импульсного лазерного нанесения магнитными примесями перспективно для возможных применений, в частности, в спиновой электронике.

\section{Финансирование работы}

Работа поддержана Российским фондом фундаментальных исследований (грант 18-29-19137_мк) и Министерством науки и высшего образования Российской Федерации (государственное задание, проект № 075-032020-191/5). 


\section{Конфликт интересов}

Авторы заявляют, что у них нет конфликта интересов.

\section{Список литературы}

[1] Z. Yang, J. Hao. J. Mater. Chem. C, 4, 8859 (2016).

[2] A.A. Voevodin, M.S. Donley. Surf. Coat. Technol., 82, 199 (1996).

[3] Y. Bleu, F. Bourquard, T. Tite, A.-S. Loir, C. Maddi, C. Donnet, F. Garrelie. Front. Chem., 6, 572 (2018).

[4] P. Kumar, P.K. Kanaujia, G.V. Prakash, A. Dewasi, I. Lahiri, A. Mitra. J. Mater. Sci., 52, 12295 (2017).

[5] K. Wang, G. Tai, K.H. Wong, S.P. Lau, W. Guo. AIP Advances, 1, 022141 (2011).

[6] S.R.S. Kumar, P.K. Nayak, M.N. Hedhili, M.A. Khan, H.N. Alshareel. Appl. Phys. Lett., 103, 192109 (2013).

[7] V.Yu. Fominski, R.I. Romanov, I.S. Vasil'evskii, D.A. Safonov, A.A. Soloviev, P.V. Zinin, K.M. Bulatov, V.P. Filonenko. Diamond Relat. Mater., 92, 299 (2019).

[8] М.Н. Дроздов, Ю.Н. Дроздов, А.И. Охапкин, С.А. Краев, М.А. Лобаев. Письма ЖТФ, 45 (2), 50 (2019).

[9] Ю.А. Данилов, М.В. Ведь, О.В. Вихрова, Н.В. Дикарева, М.Н. Дроздов, Б.Н. Звонков, В.А. Ковальский, Р.Н. Крюков, А.В. Кудрин, В.П. Лесников, П.А. Юнин, А.М. Андреев. ФТП, 54, 868 (2020).

[10] М.П. Сих. В сб.: Анализ поверхности методами оже- $и$ рентгеновской фотоэлектронной спектроскопии, под ред. Д. Бриггса, М.П. Сиха (М., Мир, 1987).

[11] О.В. Вихрова, Ю.А. Данилов, М.Н. Дроздов, Б.Н. Звонков, И.Л. Калентьева. Поверхность. РСНИ, (6), 51 (2012).

[12] A.C. Ferrari. Solid State Commun., 143, 47 (2007).

[13] A.C. Ferrari, D.M. Basco. Nature Nanotechnology, $\underline{8}, 235$ (2013).

[14] L.G. Cançado, A. Jorio, E.H. Martins Ferreira, F. Stavale, C.A. Achete, R.B. Capaz, M.V.O. Moutinho, A. Lombardo, T.S. Kulmala, A.C. Ferrari. Nano Lett., 11 (8), 3190 (2011).

[15] C.A. Klein, W.D. Straub. Phys. Rev., 123, 1581 (1961).

[16] J. Barzola-Quiquia, J.L. Yao, P. Rödiger, K. Schindler, P. Esquinazi. Phys. Status Solidi Appl. Mater. Sci., 205, 2924 (2008).

[17] A. Behnam, J.L. Johnson, Y. An, A. Biswas, A. Ural. ACS Nano, 5, 1617 (2011).

Редактор Г.А. Оганесян

\section{Doping of carbon nanolayers grown by a pulsed laser method}

Yu.A. Danilov' ${ }^{1}$, A.V. Alaferdov ${ }^{1,2}$, O.V. Vikhrova ${ }^{1}$, D.A. Zdoroveyshchev' ${ }^{1}$, V.A. Kovalskiy ${ }^{3}$, R.N. Kriukov' ${ }^{1}$, Yu.M. Kuznetsov ${ }^{1}$, V.P. Lesnikov' ${ }^{1}$, A.V. Nezhdanov ${ }^{1}$, M.N. Drozdov ${ }^{4}$

${ }^{1}$ Lobachevsky Nizhny Novgorod State University, 603022 Nizhny Novgorod, Russia

${ }^{2}$ Center for Semiconductor Components

and Nanotechnologies, University of Campinas, 13083-870 Campinas, SP, Brazil

${ }^{3}$ Institute of Microelectronics Technology

and High Purity Materials,

Russian Academy of Sciences,

142432 Chernogolovka, Moscow Region, Russia

${ }^{4}$ Institute for Physics of Microstructures,

Russian Academy of Sciences,

603950 Nizhny Novgorod, Russia

Abstract The possibilities of doping carbon layers grown by the method of pulsed laser deposition with transition metal impurities are investigated. The composition, optical and electrical parameters of structures on $\mathrm{GaAs}$ and $\mathrm{Si} / \mathrm{SiO}_{2}$ substrates are studied. It is shown that the introduction of atoms such as $\mathrm{Fe}$ modifies the magnetic properties of the layers, causing nonlinear magnetic field dependences of the Hall effect at temperatures up to $300 \mathrm{~K}$. 